SUPPLEMENT TO: A NEW SET OF ASYMMETRIC FILTERS FOR TRACKING THE SHORT-TERM TREND

\title{
IN REAL TIME
}

By Estela Bee Dagum* and Silvia Bianconcini

1. Weight systems based on $b_{q, G}$.

1.1. Weights corresponding to the 9-term symmetric filter.

$\begin{array}{rrrrrrrrr}0.31218 & 0.28804 & 0.22278 & 0.13330 & 0.044036 & 0.00000 & 0.00000 & 0.00000 & 0.00000 \\ 0.27101 & 0.31845 & 0.27101 & 0.15289 & 0.02630 & -0.03965 & 0.00000 & 0.00000 & 0.00000 \\ 0.10931 & 0.25652 & 0.32009 & 0.25652 & 0.10931 & -0.01705 & -0.03470 & 0.00000 & 0.00000 \\ -0.01544 & 0.11250 & 0.25957 & 0.32281 & 0.25957 & 0.11250 & -0.01544 & -0.03605 & 0.00000 \\ -0.03907 & -0.01074 & 0.12023 & 0.26574 & 0.32767 & 0.26574 & 0.12023 & -0.01074 & -0.03907 \\ 0.00000 & -0.03605 & -0.01544 & 0.11250 & 0.25957 & 0.32281 & 0.25957 & 0.11250 & -0.01544 \\ 0.00000 & 0.00000 & -0.03470 & -0.01705 & 0.10931 & 0.25652 & 0.32009 & 0.25652 & 0.10931 \\ 0.00000 & 0.00000 & 0.00000 & -0.03965 & 0.02630 & 0.15289 & 0.27101 & 0.31485 & 0.27101 \\ 0.00000 & 0.00000 & 0.00000 & 0.00000 & 0.04404 & 0.13330 & 0.22278 & 0.28804 & 0.31184\end{array}$

1.2. Weights corresponding to the 13-term symmetric filter.

\begin{tabular}{|c|c|c|c|c|c|c|c|c|c|c|c|c|}
\hline 0.22362 & 0.21564 & 0.19266 & 0.157478 & 0.11444 & 0.06902 & 0.02714 & & & 0.00000 & 00 & & \\
\hline 65 & 0.22352 & 0.21065 & 0.174523 & 0.12230 & 0.06460 & 0.01357 & -0.0 & & & & & \\
\hline 0.15391 & 0.21013 & 0.23100 & 0.21013 & 0.15391 & 0.08000 & 0.01250 & -0.02600 & 0.025570 & 0 & & & \\
\hline 0.06338 & 0.14212 & 0.20452 & 0.22808 & 0.20452 & 0.14212 & 0.06338 & -0.00217 & -0.02978 & -0.01617 & 0.00000 & 0.00000 & \\
\hline-0.00258 & 0.06319 & 0.14245 & 0.20533 & 0.22909 & 0.20533 & 0.14245 & 0.06319 & -0.00258 & -0.02996 & -0.01593 & 0.00000 & \\
\hline-0.02983 & 0.00060 & 0.06762 & 0.14651 & 0.20848 & 0.23179 & 0.20848 & 0.14651 & 0.06762 & 0.00060 & -0.02983 & -0.01855 & 0.00 \\
\hline-0.01986 & -0.02982 & 0.00217 & 0.07010 & 0.14921 & 0.21106 & 0.23429 & 0.21106 & 0.149208 & 0.07010 & 0.00217 & -0.02982 & 0.01 \\
\hline 0.00000 & -0.01855 & -0.02983 & 0.00066 & 0.06762 & 0.14651 & 0.20848 & 0.23179 & 0.20848 & 0.14651 & 0.06762 & 0.00060 & -0.02 \\
\hline 0.00000 & 0.00000 & -0.01593 & -0.02996 & -0.00258 & 0.06319 & 0.14245 & 0.20533 & 0.22909 & 0.20533 & 0.14245 & 0.06319 & -0.00 \\
\hline 0.00000 & 0.00000 & 0.00000 & -0.01617 & -0.02978 & -0.00217 & 0.06338 & 0.14212 & 0.20452 & 0.22808 & 0.20452 & 0.14212 & 0.0 \\
\hline 0.00000 & 0.00000 & 0.00000 & 0.00000 & -0.02557 & -0.02600 & 0.01250 & 000 & 0.15391 & 0.21013 & 0.23100 & 0.21013 & \\
\hline 0.00000 & 0.00000 & 0.00000 & 0.00000 & 0.00000 & -0.01982 & 0.01357 & 0.06460 & 0.12230 & 0.17452 & 0.21065 & 0.22352 & \\
\hline 0.00000 & 0.00000 & 0.00000 & 0.00000 & 0.00000 & 0.00000 & 0.02714 & 0.06902 & 0.11444 & 0.15748 & 0.19267 & 0.21564 & \\
\hline
\end{tabular}

Department of Statistical Sciences, University of Bologna

Via Belle Arti, 41 - 40126 Bologna, Italy

E-MAIL: *estela.beedagum@unibo.it 